\section{Correspondence on 'Interleukin 6 receptor inhibition in primary Sjögren syndrome: a multicentre double-blind randomised controlled trial'}

We read with interest the correspondence related to the article 'Interleukin 6 receptor inhibition in primary Sjögren syndrome: a multicentre double-blind randomised placebo-controlled trial' in which possible explanations for negative findings in recent phase III randomised controlled trials (RCTs) for primary Sjögren's syndrome (pSS) are discussed, including the RCT with tocilizumab. ${ }^{1-3}$ This is an important issue to raise, since there is still an unmet need for effective treatment in pSS.

As discussed in these letters, ${ }^{23}$ most recent RCTs used the European League Against Rheumatism (EULAR) Sjögren's Syndrome Disease Activity Index (ESSDAI) as primary endpoint. The ESSDAI is widely applied and seems suitable to assess systemic disease activity in clinical practice and in cohort studies in a standardised way. However, there are some limitations to the ESSDAI as primary endpoint in trials. ${ }^{4}$ In addition to the points made by our colleagues, it is important to note that in several RCTs, including the tocilizumab trial, large response rates for the ESSDAI minimal clinically important improvement ( $\geq 3$ points decrease) were seen in both the active treatment and placebo groups. ${ }^{156}$ With $>50 \%$ placebo response rates, it is very difficult to demonstrate superiority of active treatment.

As suggested by Wang et al, ${ }^{2}$ salivary and lacrimal gland-centred outcome measures might be better suited to use as endpoint. We agree this is relevant, since these organs are primarily affected in pSS. In addition, symptoms like fatigue and dryness should be evaluated, since patient-reported symptoms are important for quality of life of patients with pSS, even more than systemic disease activity. ${ }^{78}$ Also, the ESSDAI and EULAR Sjögren's Syndrome Patient Reported Index (ESSPRI) can best be used together to assess disease activity, since they are complementary indices. ${ }^{9}$ Therefore, we argue that a composite endpoint including multiple important pSS features is more appropriate than only ESSDAI or only gland function as primary endpoint in this complex disease.

Within our multidisciplinary team, we have developed the composite of relevant endpoints for Sjögren's syndrome (CRESS), consisting of five items: systemic disease activity, patient-reported symptoms, tear gland, salivary gland and serology. CRESS response is defined as achieving response on at least three of the five items. ${ }^{10}$ Since with a composite endpoint response needs to be achieved on multiple items, placebo response is expected to be lower, which is crucial to demonstrate treatment efficacy. In the tocilizumab RCT of Felten $e t a l,{ }^{1}$ ESSDAI response rates were $53 \%$ in the tocilizumab and $64 \%$ in the placebo group. Clinical, patient-reported, gland-centred and immunological outcomes showed negative results, suggesting no beneficial treatment effect from tocilizumab. Presumably, a composite endpoint could have confirmed these results with lower response rates. Another advantage is that a composite endpoint may facilitate a broader inclusion of patients with pSS, since response is not only measured by systemic disease activity, but also, for example, by improvement on fatigue and dryness. Especially in early disease, these complaints can be very prominent.

In the CRESS, both the tear and salivary gland items consist of two complementary measurements. The tear gland item includes Schirmer's Test and Ocular Staining Score (OSS) and the salivary gland item includes unstimulated whole salivary flow (UWS) and salivary gland ultrasonography (SGUS). We believe that combining two measurements, each assessing different aspects, gives a broad reflection of the glands. If OSS and SGUS are not available, the concise CRESS can be used, leaving Schirmer's Test and UWS for evaluation of these items. Besides saliva production and SGUS, salivary gland biopsy might be considered as additional tool for evaluation of the salivary glands. This would preferably be included as secondary endpoint in clinical trials, since it is not feasible to perform repeated biopsies in all patients. Although the relationship between salivary gland histopathology and clinical symptoms is not fully understood, evaluating histological changes in salivary glands is of great importance to understand the mechanism of action of a treatment, especially as salivary glands are a target organ that can easily be accessed. Measurements of interest for this evaluation are area of infiltrate $\left(\mathrm{CD} 45^{+}\right.$ fraction), B-cell and T-cell numbers, level of organisation (eg, number of $\mathrm{CD} 21^{+}$networks and germinal centres) and presence and severity of lymphoepithelial lesions. When combined with response on a composite endpoint, this would add to our understanding of which histological changes occur in patients who are (non-)responders.

To conclude, we agree with Wang et $a l^{2}$ and Felten and Gottenberg ${ }^{3}$ that improvements in trial design are needed, with focus on the choice of a valid, reliable, sensitive to change primary endpoint that lowers placebo effect and can discriminate between treatment arms. The use of a composite endpoint, combining disease activity and functional and serological parameters, like the newly developed CRESS,${ }^{10}$ would benefit the search of effective treatments in pSS.

Liseth de Wolff $\odot,{ }^{1}$ Suzanne Arends $\odot,{ }^{1}$ Gwenny M Verstappen $\odot$, 1 Arjan Vissink ๑ , ${ }^{2}$ Frans G M Kroese, ${ }^{1}$ Hendrika Bootsma $\odot^{1}$

${ }^{1}$ Rheumatology and Clinical Immunology, University Medical Centre Groningen, University of Groningen, Groningen, The Netherlands

${ }^{2}$ Oral and Maxillofacial Surgery, University Medical Centre Groningen, University of Groningen, Groningen, The Netherlands

Correspondence to Professor Hendrika Bootsma, Rheumatology and Clinical Immunology, University Medical Centre Groningen, University of Groningen, Groningen 30 001, 9700, The Netherlands; h.bootsma@umcg.nl

Contributors All authors contributed to the concept, design and writing of the letter and have approved the final version.

Funding The authors have not declared a specific grant for this research from any funding agency in the public, commercial or not-for-profit sectors.

Competing interests None declared.

Patient and public involvement Patients and/or the public were not involved in the design, or conduct, or reporting, or dissemination plans of this research.

Patient consent for publication Not required.

Provenance and peer review Not commissioned; internally peer reviewed.

(C) Author(s) (or their employer(s)) 2021. No commercial re-use. See rights and permissions. Published by BMJ.

\section{Check for updates}

To cite de Wolff L, Arends S, Verstappen GM, et al. Ann Rheum Dis Epub ahead of print: [please include Day Month Year]. doi:10.1136/annrheumdis-2021-220198

Received 19 February 2021

Accepted 20 February 2021

Ann Rheum Dis 2021;0:1. doi:10.1136/annrheumdis-2021-220198

\section{ORCID iDs}

Liseth de Wolff http://orcid.org/0000-0002-7917-5449

Suzanne Arends http://orcid.org/0000-0002-4422-7640

Gwenny M Verstappen http://orcid.org/0000-0002-5682-6085

Arjan Vissink http://orcid.org/0000-0003-2581-4361

Hendrika Bootsma http://orcid.org/0000-0001-7126-9785

\section{REFERENCES}

1 Felten R, Devauchelle-Pensec V, Seror R, et al. Interleukin 6 receptor inhibition in primary Sjögren syndrome: a multicentre double-blind randomised placebo-controlled trial. Ann Rheum Dis 2020:1-10.

2 Wang B, Chen S, Xuan J, et al. Correspondence on "Interleukin 6 receptor inhibition in primary Sjögren syndrome: a multicentre double-blind randomised placebo-controlled trial.". Ann Rheum Dis 2021:1-2.

3 Felten R, Gottenberg J-E. Response to: "Correspondence on 'Interleukin 6 receptor inhibition in primary Sjögren syndrome: a multicentre double-blind randomised placebo-controlled trial'"' by Wang, et al. Ann Rheum Dis 2021;0:1-2.

4 de Wolff L, Arends S, van Nimwegen JF, et al. Ten years of the ESSDAl: is it fit for purpose? Clin Exp Rheumatol 2020;38 (Suppl 126):283-90.

5 Baer A, Gottenberg J-E S, Clair EW, et al. Efficacy and safety of abatacept in active primary Sjögren's syndrome: results of a phase III, randomised, placebo-controlled trial. Ann Rheum Dis 2020;0:1-10.

6 van Nimwegen JF, Mossel E, van Zuiden GS, et al. Abatacept treatment for patients with early active primary Sjögren's syndrome: a single-centre, randomised, double-blind, placebo-controlled, phase 3 trial (ASAP-III study). Lancet Rheumatol 2020:1-11. doi:10.1016/S2665-9913(19)30160-2

7 Lendrem D, Mitchell S, McMeekin P, et al. Health-Related utility values of patients with primary Sjögren's syndrome and its predictors. Ann Rheum Dis 2014;73:1362-8.

8 Hammitt KM. Sjögren's: the patients' perspective. Clin Exp Rheumatol 2020;38 Suppl 126:25-6.

9 Seror R, Theander E, Brun JG, et al. Validation of EULAR primary Sjögren's syndrome disease activity (ESSDAI) and patient indexes (ESSPRI). Ann Rheum Dis 2015;74:859-66.

10 Arends S, de WolffL, van NimwegenJ, et al. Composite of Relevant Endpoints for Sjögren's Syndrome (CRESS) [abstract]. Arthritis Rheumatol 2020;72. 